\title{
An important paraplegia case due to synthetic cannabinoid bonsai abuse
}

\author{
Serkan Demir ${ }^{1}$, Hakan Simsek ${ }^{2}$, Mehmet Guney Senol ${ }^{1}$, Ahmet Eroglu ${ }^{3}$, Ergenekon Karagoz ${ }^{4}$, \\ Hakan Tekeli ${ }^{1}$, Rifat Erdem Togrul ${ }^{1}$
}

\begin{abstract}
Objective: The number of synthetic derivatives of the world's most popular and commonly abused drug, cannabis is rapidly growing day by day. Although the drug has certain applications in the medical field, due to its wide and easy access and cheapness, more people start trying the drug commonly referred to as 'Bonsai'. This synthetic form of the drug has many different names in different countries. The drug is most commonly referred as "Bonsai" in Turkey, "Spice" in UK and "K2" or "Jamaica" in the US. The synthetic cannabinoids are mainly smoked using a pipe, a hookah (or a bong), or wrapped in cigarette papers. Various cases, including the result of death, have been reported related to 'Bonsai' smoking. We present here a case of 'Bonsai' drug abuse with unusual presentation of paraplegia
\end{abstract}

Key Words: Bonsai, Cannabinoid, Paraplegia

\section{Introduction}

Cannabis was used for both medical and pleasureinducing purposes in the history. Today, it is still the most popular and commonly abused illegal drug (1). Ibn-I Sina is among the early researchers who discussed the medical utilization of cannabis in his book "El Kanun Fit-Tibbi" in 10 A.D2.

Cannabis has a wide variety of uses in medicine. By interacting different receptors, it can show antiischemic, anxiolytic, analgesic, anti-diabetic, antibacterial, anti-epileptic, spasmolytic, anti-tumoral, and anti-inflammatory effects. However, because of its likelihood of being pleasure-inducing, it is also used illegally $(2,3,4,5)$.

Marijuana is the dried leaves of the cannabis plant. It is the most popular drug abused in the US. The production of synthetic cannabinoids, as an alternative to Marijuana, initially started in 2004. The synthetic alternatives have then started to spread rapidly because of their cheapness and commercial availability. This synthetic form of the drug has many different names in different countries. The drug is most commonly referred as "Bonsai" in Turkey, "Spice" in UK and "K2" or "Jamaica" in the US. The synthetic cannabinoids are mainly smoked using a pipe, a hookah (or a bong), or wrapped in cigarette papers. There are many reports of the synthetic drug taken orally as an alternative $(6,7)$.
The greatest concern regarding the synthetic cannabinoids is their continuous change of structure. While the initially manufactured drugs mostly include JWH-018 and JWH-073, due to close regulations and safety restrictions, a large amount of side-products started to be produced (JWH-081, JWH-122, LWH210, and AM-2201). According to the report by the European Monitoring Centre for Drugs and Drug Addiction in 2012, out of the 73 psychoactive chemicals, 30 were synthetic cannabinoids. European Union warning system in 2013 included 80 different synthetic cannabinoids $(8,9)$. When inhaled, the drug's effects start within 1-2 minutes, however oral consumption of the drug may take a longer period of time to start action (10).

In the past several years, a high number of deaths have been reported related to Bonsai' abuse (11). The drug has many harmful side effects including nausea, vomiting, diffuse alveolar damage, tachycardia, abdominal pain and edema. Many patients suffer neuropsychiatric complaints. These neurologic symptoms and findings may include ataxia, coma, confusion, imbalance, headache, muscle weakness, speech impairment, paralysis, epileptic seizure, tremor, dilated pupils and nystagmus.

Received 12-05-2016 Accepted 13-06-2016 Available Online 15-06-2016

1 GATA Haydarpasa Training Hospital, Department of Neurology, Istanbul, Turkey.

2 GATA Haydarpasa Training Hospital, Department of Neurosurgery, Istanbul, Turkey.

3 Van Military Hospital, Department of Neurosurgery, Van, Turkey.

4 Van Military Hospital, Department of Infectious Diseases and Clinical Microbiology, Van, Turkey

*Corrospending Author Ahmet Eroglu E-mail: drahmeteroglu@gmail.comPhone: +90 5062036231 
In addition, psychiatric complaints including panic attack, anxiety, irritability, acute psychotic attack, hallucination, agitation, delusion and paranoia may be seen due to 'Bonsai' abuse $(12,13)$.

The patient who addicted to Bonsai usage for a while, he gave up using Bonsai due to different complaints. Although stopped drug abuse, his clinical status deteriorated and developed paraplegia. Because of its unusual effect and to get attention to potential harmful effects of Bonsai, the case has been thought as significant for presentation.

\section{Case}

The 48 year-old male patient came to our clinic with leg weakness and numbness. His occupation was a professional tourist guide. He explained that after six months of using Bonsai, he started to feel numbness in his legs and then stopped using the drug because of his complaints. He had certain pains and aches in his extremities when he first started using the drug, but ignored them. He became more wary of his condition when he started to feel numbness in his pains. He stated that his arms and upper body generally felt better compared to his legs. He also added that sometimes the numbness and the pain were so intense that he couldn't stand by his own.

His initial neurological examination revealed that his upper extremities had bilateral vague paresis (muscle strength 4/5). Lower extremities were paraplegic with the accompanying spasticity was noted.

His deep tendon reflexes were globally brisk, plantar reflexes were bilaterally extensor and Achilles klonus was present bilaterally with $4-5$ beats. There were no autonomic findings in the patient. Spinal MRIs showed a symmetrical, non-contrast-enhancing lesion which impacts on bilateral pyramidal tracts (Figures $1,2,3)$.

Cerebrospinal fluid (CSF) analysis was normal but CSF protein level was $299 \mathrm{mg} / \mathrm{dl}$ (normal range 15-45 $\mathrm{mg} / \mathrm{dl}$ ). The blood tests regarding infective, rheumatological and vasculitic diseases revealed no abnormality. Because the patient was a professional tourist guide, 'tropical spastic paraparesis' was suspected.

HTLV 1-2 virus antibodies examined and found to be as negative. Methylprednisolone $1 \mathrm{gr} /$ day was given intravenously for 10 days and a brief recovery period was observed. Intrathecal baclofen pump was used to reduce the spasticity in his legs and some progress has been achieved. The patient was also mobilized with the physical therapist. The diffuse lesions were observed to best able in the further control MRIs. Patient consent form has been approved by the patient for this presentation and article.

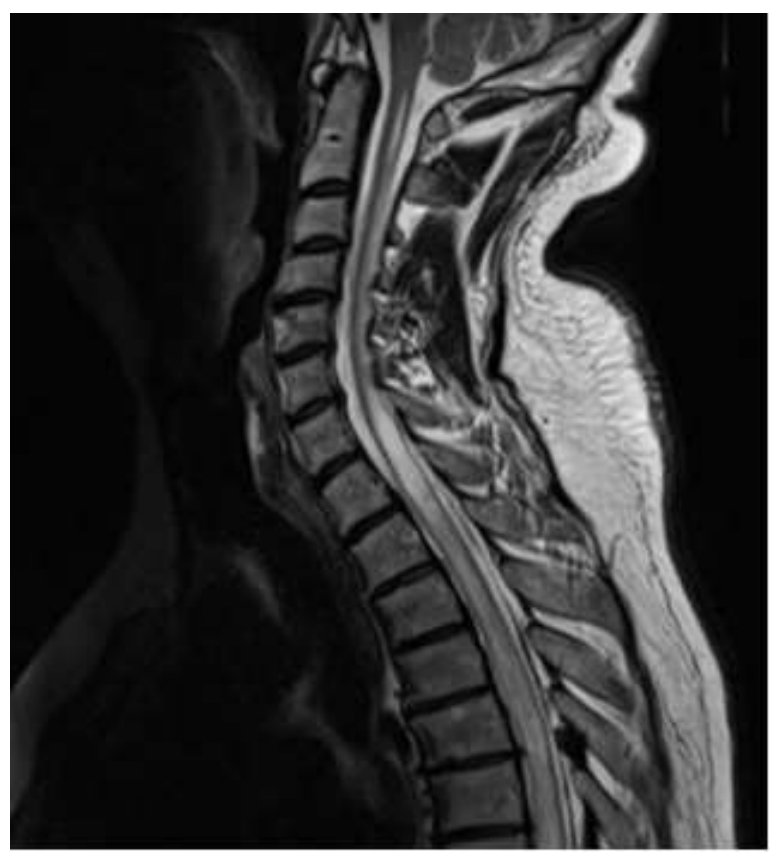

Figure 1: Cervical Spinal MRI showed a diffuse, noncontrast-enhancing lesion

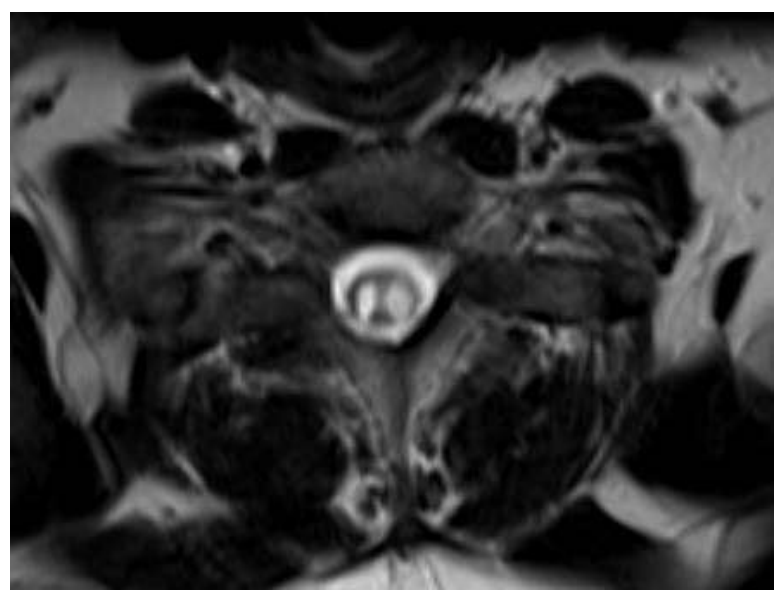

Figure 2: Cervical Spinal MRI showed a symmetrical, non-contrast-enhancing lesion which impacts on bilateral pyramidal tracts 


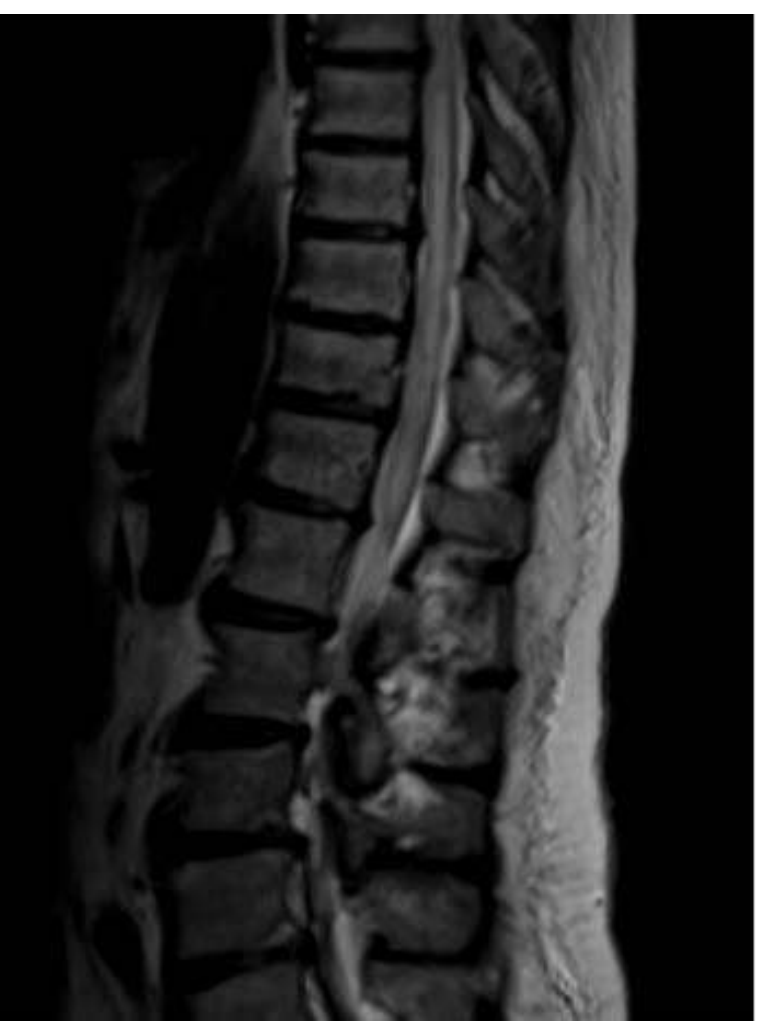

Figure 3: Dorsal and Lomber Spinal MRI showed a diffuse non-contrast-enhancing lesion which impacts on pyramidal tracts

\section{Discussion}

New synthetic forms of cannabis, a plant which was used for both medical applications and pleasureinducing effects in the past, have been developed in recent years. Commonly referred as 'Bonsai' in our country, Turkey, these synthetic drugs are widely abused due to their cheapness and easy accessibility.

There are many reported cases of death because of the 'Bonsai' use. Texas Toxin Center's research with 464 participants revealed that $43 \%$ had cardiac, $61.9 \%$ had neuropsychiatric and $21.1 \%$ had gastrointestinal symptoms. $41 \%$ of 464 participants were below 19 years old and the majority of the patients were male (13). Another research in 2010 by the USA National Toxin Center indicated that the most common adverse sign was tachycardia with $37.7 \%$ in 1353 patients. In the same research it was reported that $88.2 \%$ of the complaints had acute onset and there was only one death (14). Many different clinical presentations found to be reported in the current literature. Our case was unique regarding the patient's complaints have a subacute onset, the patient presents a relatively rare neurologic deficit (paraplegia) and the patient is older in age (48 year old). According to the data from the research of Texas Toxin Center, only $0.2 \%$ of the patients had paralysis. As far as to be known, there is only one paper reports generalized paraplegia due to abuse of the synthetic drug "Ninja Strong" (15). It should be noted that serious neurological symptoms, such as muscle weakness, are quite rare.

Hereditary spastic paraplegia was ruled out because of the proven spinal involvement with imaging and his age. Another possible diagnosis, tropical spastic paraparesis was also ruled out since the HTLV 1-2 antibodies were negative. Slightly increased CSF protein levels has been reported, however our patient had a level that was 6 times above the average (16). Although we have noted that the pyramidal tracts were affected across the spine bilaterally and symmetrically in spinal MRIs, we are unable to figure out why the upper extremities were rather unaffected.

\section{Conclusion}

Our patient partially benefited from the administration of high dose IV corticosteroids. He also highly benefited from the intrathecal baclofen pump which was used to reduce the spasticity. He was able to walk with support after physical rehabilitation

Conflict of Interest: The authors declare no potential conflicts of interest with respect to the research, authorship, and/or publication of this article.

Ethical issues: All Authors declare that Originality of research/article etc... and ethical approval of research, and responsibilities of research against local ethics commission are under the Authors responsibilities. The study was completed due to defined rules by the Local Ethics Commission guidelines and audits.

Acknowledgement: None

\section{Reference}

1. Vandrey R, Dunn KE, Fry JA, Girling ER. A survey study to characterize use of Spice products (synthetic cannabinoids). Drug and alcohol dependence. 2012 Jan $1 ; 120(1): 238-41$.

2. Pertwee RG. Pharmacological actions of cannabinoids. InCannabinoids 2005 (pp. 1-51). Springer Berlin Heidelberg.

3. Albayrak S, Suiçmez S, Calikoğlu F. [The use of Aloe and Urtica species in Avicenna's canon of medicine]. Yeni tip tarihi arastirmalari $=$ The new history of medicine studies. 2003 Dec(10-11):95-120.

4. Fantegrossi WE, Moran JH, Radominska-Pandya A Prather PL. Distinct pharmacology and metabolism of K2 synthetic cannabinoids compared to $\triangle 9$-THC: mechanism underlying greater toxicity?. Life sciences. 2014 Feb 27;97(1):45-54

5. Hoyte CO, Jacob J, Monte AA, Al-Jumaan M, Bronstein AC, Heard KJ. A characterization of synthetic cannabinoid exposures reported to the National Poison Data System in 2010. Annals of emergency medicine. 2012 Oct $31 ; 60(4): 435-8$

6. Ashton JC. Cannabinoids for the treatment of inflammation. Current opinion in investigational drugs (London, England: 2000). 2007 May;8(5):373-84. 
7. Hermanns - Clausen M, Kneisel S, Szabo B, Auwärter V. Acute toxicity due to the confirmed consumption of synthetic cannabinoids: clinical and laboratory findings. Addiction. 2013 Mar 1;108(3):534-44.

8. Spaderna M, Addy PH, D’Souza DC. Spicing things up synthetic cannabinoids. Psychopharmacology. 2013 Aug $1 ; 228(4): 525-40$

9. Forrester MB, Kleinschmidt K, Schwarz E, Young A Synthetic cannabinoid exposures reported to Texas poison centers. Journal of addictive diseases. 2011 Oct $1 ; 30(4): 351-8$

10. Gurdal F, Asirdizer M, Aker RG, Korkut S, Gocer Y, Kucukibrahimoglu EE, Ince $\mathrm{CH}$. Review of detection frequency and type of synthetic cannabinoids in herbal compounds analyzed by Istanbul Narcotic Department of the Council of Forensic Medicine, Turkey. Journal of forensic and legal medicine. 2013 Aug 31;20(6):667-72.

11. Griffiths P, Mounteney J, Lopez D, Zobel F, Götz W Addiction research centres and the nurturing of creativity. Monitoring the European drug situation: the ongoing challenge for the European Monitoring Centre for Drugs and Drug Addiction (EMCDDA). Addiction. 2012 Feb $1 ; 107(2): 254-8$
12. Greineisen WE, Turner H. Immunoactive effects of cannabinoids: considerations for the therapeutic use of cannabinoid receptor agonists and antagonists. International immunopharmacology. 2010 May 31;10(5):547-55

13. Gessain A, Mahieux R. Tropical spastic paraparesis and HTLV-1 associated myelopathy: clinical, epidemiological, virological and therapeutic aspects. Revue neurologique. 2012 Mar 31;168(3):257-69.

14. Kronstrand R, Roman M, Andersson M, Eklund A. Toxicological findings of synthetic cannabinoids in recreational users. Journal of analytical toxicology. 2013 Oct 1;37(8):534-41.

15. Papaseit E, Farré M, Schifano F, Torrens M. Emerging drugs in Europe. Current opinion in psychiatry. $2014 \mathrm{Jul}$ $1 ; 27(4): 243-50$

16. Singh J, Budhiraja S. Therapeutic potential of cannabinoid receptor ligands: current status. Methods Find Exp Clin Pharmacol. 2006 Apr 1;28(3):177. 